\title{
Exercise addiction - cases, possible indicators and open questions
}

\section{DEPRESSION \\ PERFORMANCE \\ RECOVERY \\ RED-S \\ SPORTS AND SOCIETY \\ SPORTS NUTRITION}

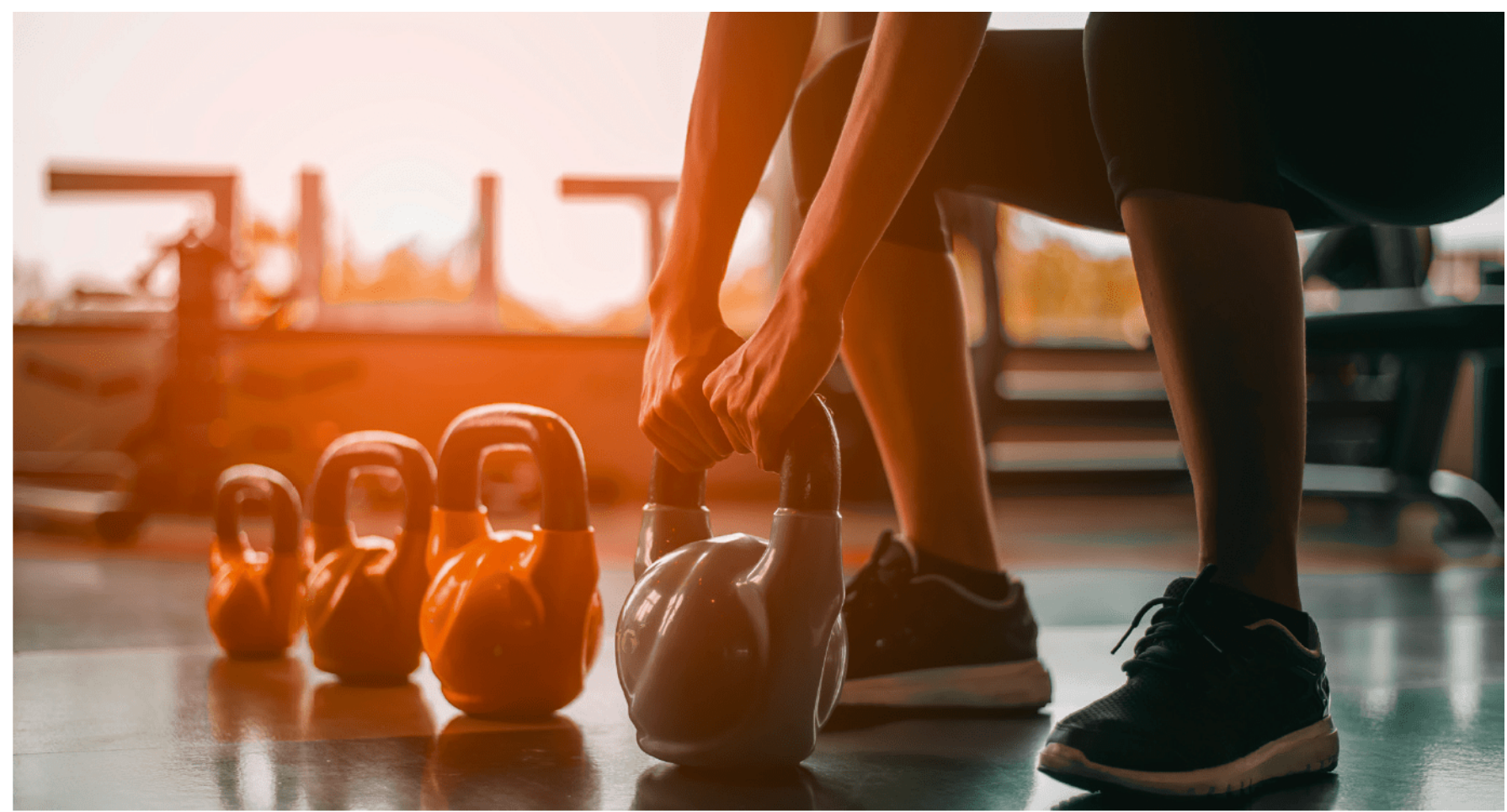

\section{Colledge Flora}

University of Basel

\begin{abstract}
While addictive disorders involving substances are well researched, the field of behavioral addictions, including exercise addiction, is in its infancy. Although exercise addiction is not yet recognized as a psychiatric disorder, evidence for the burden it imposes has gained attention in the last decade.

Characterised by a rigid exercise schedule, the prioritization of exercise over one's own health, family and professional life, and mental wellbeing, and extreme distress when exercise is halted, the phenomenon shares many feature with substance use disorders. While prevalence is thought to be low, affecting one in every 1000 exercisers, current research suggests that the symptoms are extremely burdensome, and may often be accompanied by other psychiatric disorders. It is no longer thought to be the case that only endurance athletes are at risk. While disease history and neural substrates are still to be clarified, there are a number of indicators which may help clinicians and sports physicians identify a possible case of
\end{abstract}


exercise addiction.

\section{Zusammenfassung}

Substanzgebundene Suchterkrankungen sind gut recherchiert; im Gegensatz dazu ist die Forschung hinsichtlich Verhaltenssüchte, unter anderem auch Bewegungssucht, noch nicht etabliert. Bewegungssucht wurde noch nicht als psychische Störung eingestuft, die belastenden Symptome haben allerdings in den letzten zehn Jahren viel Aufmerksamkeit generiert. Die Symptome ähneln denjenigen von substanzgebundenen Süchten; ein rigides Konsummuster, die Vernachlässigung von Familie, Beruf und der eigenen Gesundheit, und ein starkes psychisches Leid, wenn die Aktivität oder die Bewegung unterbrochen werden muss. Die Prävalenz ist gemäss Einschätzungen gering; vermutlich ist jede tausendste sporttreibende Person betroffen. Jedoch sind die Symptome für den Betroffenen schwerwiegend, und andere psychische Störungen sind häufig vorhanden. Es wird nicht mehr angenommen, dass nur Ausdauerathleten betroffen sein können. Der Krankheitsverlauf und die neuronalen Substrate bleiben noch ungeklärt. Es gibt jedoch verschiedene Hinweise, welche für Mediziner und Sportärzte bei der Identifikation einer möglichen Bewegungssucht von Nutzen sein können.

\section{Introduction}

Substance use disorders impose a large disease burden globally. In 2016, addiction to alcohol and drugs was responsible for 131 million Disability Adjusted Life Years (DALYS) [1]; this is more than half as many as for all forms of cancer in 2015 [2], and over eight times as many as for major depressive disorders in 2010 [3]. These quantifiable harms arise from the fact that substance use disorders have clear and measurable physical health effects. By contrast, quantifying the harm caused by behavioral addictions is still a topic of discussion [4], as the harms resulting from these disorders are not solely, or even chiefly, physical, but more psychological (e.g., inability to concentrate) or even social (e.g., neglecting familial relationships) in nature.

In recent decades, behavioral addictions have been receiving increasing attention as potentially important burdens on human health. As noted by Thibaut (2017): “...there is no habit which provides reward that cannot become excessive, compulsive, and sometimes life-endangering.” [5] While gambling is the most well-known form of behavioral addiction, and the only one to date listed in the DSM-5 as a non-substance related disorder, activities such as shopping, internet use and exercise have also been the focus of research [6].

\section{Exercise addiction - symptoms and prevalence}

Exercise has drawn much attention as a potential form of behavioral addiction in the past 20 years, as cross-sectional questionnaires have built on early case studies reporting individuals who exercise to the point of extreme illness, breaking bones, and beyond [7]. These case studies list self-reported symptoms such as a compelling urge to exercise for a certain amount of time each day [8], severe negative affect when this is not possible [9], suicidal ideation [10], continuance despite a recognition of the unhealthy role of exercise on physical health and mental wellbeing [11], and the neglect of professional and social responsibilities [12]. For example, Griffiths (1997) reports on the case of a young woman who ends her 
relationship, leaves an exam early, and trains through severe pain to pursue her athletic hobby [13]; Spieker (1996) reports on a pregnant woman running despite a femoral stress fracture, und suffering depressive symptoms when forced to stop [14]; and Kotbagi and colleagues (2014) present the case of a male cyclist who changes his job and suffers severe problems in his marriage due to his prioritizing training to the virtual exclusion of all else [15]. These symptoms resemble the classic substance use disorder symptoms described in the DSM-5, prompting researchers to discuss exercise in terms of a behavioral addiction.

More recent cross-sectional data have established that a number of exercising individuals appear to suffer psychiatric distress linked to their habits, but feel unable to stop. These studies indicate that men are more frequently affected

[16,17], but the initially posited notion that only endurance athletes are affected does not appear to hold true, with evidence for a comparable prevalence in team sports [18].

Conservative prevalence estimates suggest that every 1'000th exercising individual displays marked symptoms of exercise addiction, while every 10'000th may require some form of psychiatric treatment [19]. Symptoms of exercise addiction occur with most frequency in individuals with eating disorders; indeed, it has been suggested by some researchers that exercise addiction is only observable in individuals with eating disorders [20] Exercise (at a level deemed to be damaging to health) is used by between 39\% [21] and 45\% [22] of this population to accelerate weight loss or purge calories consumed. However, there is now robust evidence that individuals without any symptoms of eating disorders also suffer from exercise addiction; several studies have specifically excluded those with eating disorders from their samples, and have still found symptoms of exercise addiction [23-25]. The terms "primary" and "secondary" exercise addiction have been used to distinguish between those who exercise excessively because they find (or found) exercise to be highly rewarding, and those who exercise excessively in order to achieve some other goal, respectively [26]. It has been suggested that the primary form of exercise addiction may more closely resemble substance use disorders, while the secondary form may be more akin to a compulsion [27]. Consequently, individuals with eating disorders may be said to suffer from secondary exercise addiction. Whether a distinction will be made between primary exercise addiction as a behavioral addiction, and secondary exercise addiction as a symptom or symptom cluster, remains to be determined.

\section{Psychiatric profile}

A small number of studies have addressed other psychiatric disorders which present in individuals affected by exercise addiction. These studies suggest that those at risk for exercise addiction also suffer from symptoms of anxiety [28], depression [29], and other addictive disorders [30,31]. At this stage, results must be interpreted with caution; the majority of these studies are based on self-report questionnaires, rather than clinical diagnoses, and so can be viewed as indicating avenues for more detailed study. It is also interesting to note that while, at this stage, these studies provide no indication about whether other disorders may cause, or result from, exercise addiction [32], they could also provide first insights into the course of exercise addiction. For example, individuals reporting exercise addiction also report symptoms of depression and anxiety when obliged to stop exercising [9,33]. The antidepressant effects of exercise are well-documented, and around the time that the concept of exercise addiction was emerging, authors were suggesting that it might be a form of self-medication for severe depression [34]. A study of ultramarathon 
runners identified rates of $20 \%$ for depressive symptoms and risk of exercise addiction, separately [35]. High levels of narcissism have also been found to predict risk of exercise addiction [36]. Additionally, as Bamber and colleagues note, “... studies of negative affect have tended to focus on psychological responses to exercise withdrawal; there has been little attention paid to whether psychological disturbance and distress are generally characteristic of exercise dependence.” [37] In spite of the fact that over 100 cross-sectional studies have addressed the phenomenon of exercise addiction [38], the evidence for its inclusion in the DSM is still considered insufficient. This is due in part to the fact that simple questionnaire studies do not provide detailed information about the psychiatric status of affected individuals; as a result, the above-mentioned issues about the course and causes of this phenomenon, and the psychiatric profile of those at risk, remain to be clarified. However, the questionnaires currently employed to assess risk for exercise addiction also vary. While some, such as the Exercise Addiction Inventory (6 questions, Table 1), are brief, with rather vague questions [39], others, such as the Exercise Dependence Scale (21 questions, Table 2) emphasize the negative consequences of exercise habits in more detail [40]. This variability has led not only to varying prevalence estimates [41] but also to the need for a careful interpretation of the values that individuals ascribe to the statements in these questionnaires [42]. For example, professional athletes, or those who take their exercise activities very seriously, may well increase their training volume over time, feel uncomfortable if they miss a training session, and make certain sacrifices for their training; however, these facts do not impose a psychological burden on them, or indicate behavior that is incompatible with normal living. As with other behavioral addictions, the behavior itself is not unhealthy per se [43], and in the case of exercise, may indeed be a key part of human wellbeing. In considering the point at which this habit becomes an addiction, it is therefore essential to ascertain whether burdensome negative consequences are present, and whether these cause psychological and, potentially, physical suffering. 


\section{Instructions: using the scale provided, complete each question concerning your current feelings about your exercise behavior.}

1

2

Strongly disagree
3

1. Exercise is the most important thing in my life.

4

4
5

Strongly agree

2. Conflicts have arisen between me and my family and/ or my partner about the amount of exercisel.

3. I use exercise as a way of changing my mood (e.g. to get a buzz, to escape, etc.).

4. Over time I have increased the amount of exercise I do in a day.

5. If I have to miss an exercise session I feel moody and irritable.

6. If I cut down the amount of exercise I do, and then start again, I always end up exercising as often as I did before. 
Instructions: using the scale provided below, please complete the following questions as honestly as possible. The questions refer to current exercise beliefs and behaviors that have occurred in the past 3 months. Please place your answer in the blank space provided after each statement.
1
2
3
4
5
6

Never

Always

1. I exercise to avoid feeling irritable

2. I exercise despite recurring physical problems

3. I continually increase my exercise intensity to achieve the desired effects/benefits.

4. I am unable to reduce how long I exercise.

5. I would rather exercise than spend time with family/ friends.

6. I spend a lot of time exercising

7. I exercise longer than I intend.

8. I exercise to avoid feeling anxious

9. I exercise when injured

10. I continually increase my exercise frequency to achieve the desired effects/benefits.

11. I am unable to reduce how often I exercise.

12. I think about exercise when I should be concentrating on school/work.

13. I spend most of my free time exercising.

14. I exercise longer than I expect.

15. I exercise to avoid feeling tense.

16. I exercise despite persistent physical problems

17. I continually increase my exercise duration to achieve the desired effects/benefits.

18. I am unable to reduce how intense I exercise

19. I choose to exercise so that I can get out of spending time with family/friends.

20. A great deal of my time is spent exercising

21. I exercise longer than I plan. 


\section{Neural substrates}

A further gap in the field of research into exercise addiction is the fact that almost no studies have examined whether neural activity in this population differs from non-addicted individuals, as is the case with other substance use disorders. A small number of studies have used imaging techniques to determine which areas of the brain may be responsible for the pleasurable feelings induced by exercise. In their review of the literature, Cheval and colleagues (2018) report that studies examining neural responses to exercise image stimuli using MRI found increased activity in certain reward-related regions of the brain, although not in the nucleus accumbens [44]. However, of the groups examined, none were recruited on the basis of exercise addiction scores. To date, only one study has assessed neural activity individuals with exercise addiction. Huang and colleagues (2019) demonstrated that, compared to non-addicted individuals, those at risk for exercise addiction showed inhibited responses to visual stimuli, in particular to nonexercise images [45]. While interesting, these findings shed little light on the rewarding or addictive nature of exercise, as the brain regions examined are at most only tangentially implicated in human reward processing.

\section{Overtraining}

Finally, research to date has focused primarily on the psychiatric aspects of exercise as an addictive disorder. This is justified to some degree, as the components of compulsion and psychiatric and emotional distress, which are hallmarks of addictive disorders, fall within the realm of psychiatric research and categorization. However, unlike certain other behavioral addictions, such as gambling or internet use, exercise addiction is likely to result in physiological damage as well. While the treatment of exerciserelated injuries is the domain of sports medicine, a better understanding of the concept of exercise addiction may be a valuable cornerstone in current approaches to overuse injuries, and the overtraining syndrome [46]. Exercise addiction may precipitate these physiological issues, or exacerbate them, and if this underlying psychological factor is completely ignored, the patient's recovery will be compromised. Conversely, overtraining may lead to a level of exhaustion which depletes psychological reserves, and consequently the affected individual reports some of the mentally burdensome symptoms which characterize exercise addiction [47]. Individuals presenting with complaints relating to overuse and overtraining may benefit from being asked a few brief questions concerning their exercise habits, even (perhaps especially) if they are not high-level athletes; key issues to address are summarized below.

\section{Practical implications}

While research into exercise addiction is in an early stage, and clinical approaches are in their infancy, it is still possible to make a number of statements, based on the literature, which may be useful to clinicians who confront suspected cases. The following indicators may be cause to ask more specifically about exercise habits, employ a simple screening tool, such as the Exercise Dependence Scale, or consider referral to a psychiatrist or psychologist: 
- The individual reports a strict exercise regime that they do not (or very rarely) deviate from.

- Exercise patterns and volume are not, or only slightly, reduced by illness or injury.

- Exercise is not enjoyed or pursued with passion, but "must" be done.

- Symptoms of depression, anxiety or disordered eating are present, or have been in the patient's history.

- The individual has unrealistic goals for, and/or expectations of, themselves.

- Factors such as participation in professional sports or competition do not adequately explain the exercise behavior and symptoms experienced.

\section{Corresponding author}

Flora Colledge, $\mathrm{PhD}$

Department of Sport,

Exercise and Health,

University of Basel, Birsstrasse 320b,

4052 Basel, Switzerland

Tel: 0041612074787

Email: flora.colledge@unibas.ch $\square$

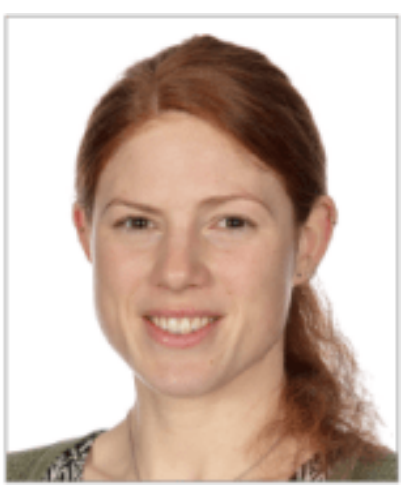

\section{References}

1. Degenhardt L, Charlson F, Ferrari A, Santomauro D, Erskine H, Mantilla-Herrara A, et al. The global burden of disease attributable to alcohol and drug use in 195 countries and territories, 1990-2013;2016: a systematic analysis for the Global Burden of Disease Study 2016. The Lancet Psychiatry. 2018;5(12):987-1012.

2. Fitzmaurice C, Allen C, Barber RM, Barregard L, Bhutta ZA, et al. Global, Regional, and National Cancer Incidence, Mortality, Years of Life Lost, Years Lived With Disability, and Disability-Adjusted Life-years for 32 Cancer Groups, 1990 to 2015: A Systematic Analysis for the Global Burden of Disease Study. JAMA Oncol. 2017;3(4):524-48.

3. Ferrari AJ, Charlson FJ, Norman RE, Patten SB, Freedman G, Murray CJL, et al. Burden of Depressive Disorders by Country, Sex, Age, and Year: Findings from the Global Burden of Disease Study 2010. PLoS Med. 2013;10(11):e1001547.

4. Delfabbro P, King DL. Challenges in the Conceptualisation and Measurement of Gambling-Related Harm. J Gambl Stud. 2019; 35(3):743-55.

5. Thibaut F, Hoehe M. Addictive behaviors: where do we stand, and where are we going? Dialogues Clin Neurosci. 2017;19(3):215-.

6. Billieux J, Schimmenti A, Khazaal Y, Maurage P, Heeren A. Are we overpathologizing everyday life? A tenable blueprint for behavioral addiction research. Journal of behavioral addictions. 2015;4(3):119-23.

7. Freimuth M, Moniz S, Kim SR. Clarifying Exercise Addiction: Differential Diagnosis, Co-occurring Disorders, and Phases of Addiction. Int J Environ Res Public Health. 2011;8(10):4069.

8. Long CGJJoMH. Assessment and managem ent of eating disordered patients who over-exercise: A four-year follow-up of six single case studies. 1995;4(3):309-16. 
9. Vitale C, Santangelo G, Verde F, Amboni M, Sorrentino G, Grossi D, et al. Exercise dependence induced by pramipexole in Parkinson's Disease-a case report. Mov Disord. 2010;25(16):2893-4.

10. Duffy ME, Rogers ML, Joiner TE. Body trust as a moderator of the association between exercise dependence and suicidality. Compr Psychiatry. 2018;85:30-5.

11. Long C, Smith J. Treatment of Compulsive Over-exercising in Anorexia Nervosa: A Case Study. Behav Cogn Psychother. 1990;18(4):295-306.

12. Bamber D, Cockerill IM, Rodgers S, Carroll D. "It's exercise or nothing”: a qualitative analysis of exercise dependence. Br J Sports Med. 2000;34(6):423-30.

13. Griffiths M. Exercise Addiction: A Case Study. Addiction Research. 1997;5(2):161-8.

14. Spieker MR. Exercise dependence in a pregnant runner. J Am Board Fam Pract. 1996;9(2):118-21.

15. Kotbagi G, Muller I, Romo L, Kern L. Pratique problématique d'exercice physique: un cas clinique. Annales Médico-psychologiques, revue psychiatrique. 2014;172(10):883-7.

16. Szabo AP, De La Vega R, Ruiz-Barquín R, Rivera O. Exercise addiction in Spanish athletes: Investigation of the roles of gender, social context and level of involvement. 2013;2(4):249-52.

17. Dumitru D, Dumitru T, Maher AJJoPE, Sport. A systematic review of exercise addiction: examining gender differences. 2018;18(3):1738-47.

18. Lichtenstein MB, Larsen KS, Christiansen E, Støving RK, Bredahl TVG. Exercise addiction in team sport and individual sport: Prevalences and validation of the exercise addiction inventory. Addiction Research \& Theory. 2014;22(5):431-7.

19. Breuer S, Kleinert J. Primäre Sportsucht und bewegungs-bezogene Abhängigkeit—Beschreibung, Erklärung und Diagnostik. Rausch ohne Drogen: Springer; 2009. p. 191-218.

20. Bamber D, Cockerill IM, Carroll D. The pathological status of exercise dependence. Br J Sports Med. 2000;34(2):125-32.

21. Shroff H, Reba L, Thornton LM, Tozzi F, Klump KL, Berrettini WH, et al. Features associated with excessive exercise in women with eating disorders. 2006;39(6):454-61.

22. Dalle Grave R, Calugi S, Marchesini G. Compulsive exercise to control shape or weight in eating disorders: prevalence, associated features, and treatment outcome. Compr Psychiatry. 2008;49(4):346-52.

23. Grandi S, Clementi C, Guidi J, Benassi M, Tossani E. Personality characteristics and psychological distress associated with primary exercise dependence: An exploratory study. Psychiatry Res. 2011;189(2):270-5.

24. Blaydon MJ, Linder KJ, Kerr JH. Metamotivational characteristics of exercise dependence and eating disorders in highly active amateur sport participants. Pers Individ Dif. 2004;36(6):1419-32.

25. Cook B, Luke R. Primary and secondary exercise dependence in a sample of cyclists. International journal of mental health and addiction. 2017;15(2):444-51.

26. Veale DMWC. Exercise Dependence. Br J Addict. 1987;82(7):735-40.

27. Cunningham HE, Pearman S, 3rd, Brewerton TD. Conceptualizing primary and secondary pathological exercise using available measures of excessive exercise. Int J Eat Disord. 2016;49(8):778-92.

28. Mayolas-Pi C, Simon-Grima J, Penarrubia-Lozano C, Munguia-Izquierdo D, Moliner-Urdiales D, LegazArrese A. Exercise addiction risk and health in male and female amateur endurance cyclists. Journal of behavioral addictions. 2017;6(1):74-83.

29. Weinstein A, Maayan G, Weinstein Y. A study on the relationship between compulsive exercise, depression and anxiety. Journal of behavioral addictions. 2015;4(4):315-8.

30. Muller A, Loeber S, Sochtig J, Te Wildt B, De Zwaan M. Risk for exercise dependence, eating disorder pathology, alcohol use disorder and addictive behaviors among clients of fitness centers. Journal of behavioral addictions. 2015;4(4):273-80.

31. Lejoyeux M, Guillot C, Chalvin F, Petit A, Lequen V. Exercise dependence among customers from a 
Parisian sport shop. Journal of behavioral addictions. 2012;1(1):28-34.

32. Starcevic V, Khazaal Y. Relationships between Behavioural Addictions and Psychiatric Disorders: What Is Known and What Is Yet to Be Learned? Front Psychiatry [Internet]. 2017 2017; 8:[53 p.]. Available from: http://europepmc.org/abstract/MED/28439243 https://doi.org/10.3389/fpsyt.2017.00053.

33. Johnston O, Reilly J, Kremer J. Excessive exercise: From quantitative categorisation to a qualitative continuum approach. 2011;19(3):237-48.

34. Garner DM, Garfinkel PE, Bemis KM. A multidimensional psychotherapy for anorexia nervosa. Int J Eat Disord. 1982;1(2):3-46.

35. Buck K, Spittler J, Reed A, Khodaee M. Psychological Attributes of Ultramarathoners. Wilderness Environ Med. 2018;29(1):66-71.

36. Bruno A, Quattrone D, Scimeca G, Cicciarelli C, Romeo VM, Pandolfo G, et al. Unraveling exercise addiction: the role of narcissism and self-esteem. Journal of addiction. 2014;2014:987841.

37. Bamber DJ, Cockerill IM, Rodgers S, Carroll D. Diagnostic criteria for exercise dependence in women. Br J Sports Med. 2003;37(5):393-400.

38. Colledge F, Buchner UG, Schmidt A, Walter M. Does exercise addiction exist? A brief review on current measurement tools and future directions. Mental Health and Addiction Research. 2019;4:1-4.

39. Griffiths MD, Szabo A, Terry A. The exercise addiction inventory: a quick and easy screening tool for health practitioners. Br J Sports Med. 2005;39(6):e30.

40. Hausenblas HA, Downs DS. How much is too much? The development and validation of the exercise dependence scale. Psychology and health. 2002;17(4):387-404.

41. Cook B, Karr TM, Zunker C, Mitchell JE, Thompson R, Sherman R, et al. Primary and secondary exercise dependence in a communitybased sample of road race runners. J Sport Exerc Psychol. 2013; 35(5):464-9.

42. Szabo A, Griffiths MD, de La Vega Marcos R, Mervó B, Demetrovics Z. Methodological and Conceptual Limitations in Exercise Addiction Research. The Yale Journal of Biology and Medicine. 2015; 88(3):303-8.

43. Kardefelt-Winther D, Heeren A, Schimmenti A, van Rooij A, Maurage P, Carras M, et al. How can we conceptualize behavioural addiction without pathologizing common behaviours? Addiction. 2017;112(10):1709-15.

44. Cheval B, Radel R, Neva JL, Boyd LA, Swinnen SP, Sander D, et al. Behavioral and Neural Evidence of the Rewarding Value of Exercise Behaviors: A Systematic Review. Sports Med. 2018;48(6):1389-404.

45. Huang Q, Huang J, Chen Y, Lin D, Xu S, Wei J, et al. Overactivation of the Reward System and Deficient Inhibition in Exercise Addiction. Med Sci Sports Exerc. 2019;51(9):1918-27.

46. Delimaris I. Potential adverse biological effects of excessive exercise and overtraining among healthy individuals. Acta Medica Martiniana. 2014;14(3):5.

47. Adams J, Kirkby R. Exercise Dependence and Overtraining: The Physiological and Psychological Consequences of Excessive Exercise. Sports Medicine, Training and Rehabilitation. 2001;10(3):199-222. 